\title{
DC field emission scanning measurements on electropolished niobium samples
}

\author{
A. Dangwal ${ }^{\mathrm{a}, \mathrm{b}, *}$, D. Reschke ${ }^{\mathrm{b}}$, G. Müller ${ }^{\mathrm{a}}$

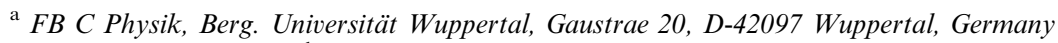 \\ ${ }^{\mathrm{b}}$ DESY, D-22603 Hamburg, Germany
}

Available online 8 May 2006

\begin{abstract}
Electropolished (EP) $\mathrm{Nb}$ samples were investigated by a dc field emission scanning microscope, which has recently been modernized for the fast scans on large samples. Measurements on EP samples before and after high pressure rinsing (HPR) are compared. Reproducible voltage scans at various surface fields have been obtained partially down to $\mu \mathrm{m}$ resolution. The statistical overview of the density of emitting sites at $120 \mathrm{MV} / \mathrm{m}$ shows a reduction from about 30 before to 14 emitters $/ \mathrm{cm}^{2}$ after HPR. Local measurements of selected emitters prove increased onset fields $E_{\text {on }}$ at $1 \mathrm{nA}$ and decreased values after HPR. High resolution SEM images and EDX measurements of the identified emitters will also be presented.
\end{abstract}

(C) 2006 Elsevier B.V. All rights reserved.

Keywords: Field emission; Scanning microscope; Electropolishing; Niobium; High pressure rinsing

\section{Introduction}

Enhanced field emission (EFE) from particulates and surface irregularities is one major obstacle which has to be overcome for efficient high gradient operation of superconducting niobium cavities. Accelerating gradients up to 30 (40) $\mathrm{MV} / \mathrm{m}$, corresponding to peak electric surface fields of about $60(80) \mathrm{MV} / \mathrm{m}$ at the cavity irises, are envisaged for accelerators like the X-ray free electron laser (XFEL) approved at DESY [1] and the international linear collider (ILC) under design now [2], respectively.

In order to avoid EFE in these cavities reliably, typical field emitters on $\mathrm{Nb}$ surfaces resulting from the actual surface preparation techniques must be identified. Since electropolished (EP) $\mathrm{Nb}$ surfaces are considered to improve the achievable cavity fields, we have started to investigate large area EP Nb samples by means of the dc field emission scanning microscope (FESM) [3]. This apparatus has recently been modernized with new hardware components

\footnotetext{
* Corresponding author.

E-mail address: arti@physik.uni-wuppertal.de (A. Dangwal).
}

(Keithley picoamperemeter with $1 \mathrm{kHz}$ rate, FUG power supply with PID regulation) [4] and LabVIEW based programs, resulting in fast voltage scans of large samples thus improving the statistics of the FESM measurements.

First results of voltage scans up to $120 \mathrm{MV} / \mathrm{m}$ with a successive change of resolution by anode tip diameters ranging from $300 \mu \mathrm{m}$ to $2 \mu \mathrm{m}$ and local measurements are presented. The density of emitting sites, onset field $E_{\text {on }}$ at $1 \mathrm{nA}$ and values of localized emitters will be compared on a $\mathrm{EP} \mathrm{Nb}$ sample before and after high pressure rinsing (HPR). High resolution SEM images and EDX analysis of selected emitting sites will also be presented.

\section{Experimental}

Two $\mathrm{Nb}$ samples of $28 \mathrm{~mm}$ diameter previously tested after buffered chemical polishing [5] were electropolished $(140 \mu \mathrm{m})$ and clean water rinsed at CEA Saclay. Contamination of these samples was avoided by clean room assembly and a special transport system which has been opened inside the load lock of the field emission scanning microscope at $10^{-6}$ mbar. For comparison, one sample (SEP2) 


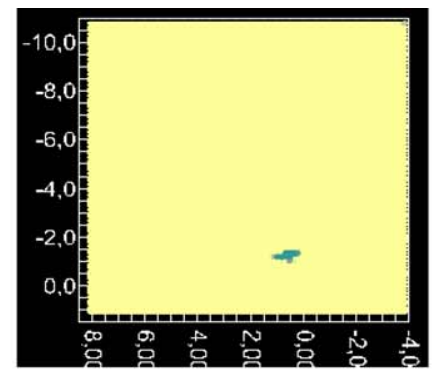

(a) $\mathrm{E}=40 \mathrm{MV} / \mathrm{m}, 1$ emitter

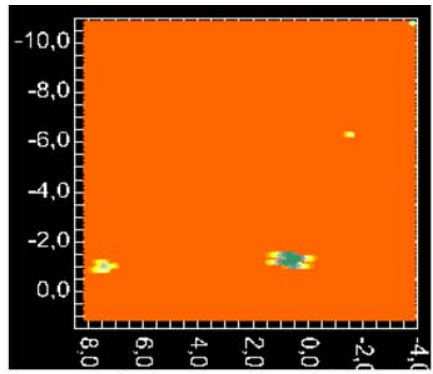

(b) $\mathrm{E}=60 \mathrm{MV} / \mathrm{m}, 3$ emitters

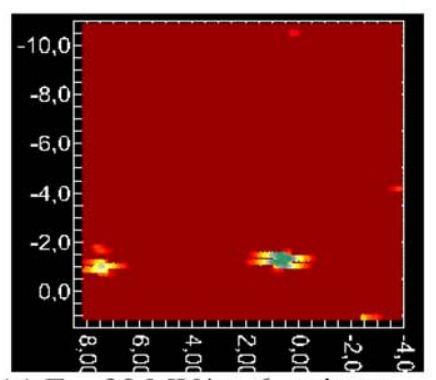

(c) $\mathrm{E}=90 \mathrm{MV} / \mathrm{m}, 6$ emitters

1 ${ }^{\text {st }}$ Series: $\varnothing_{\text {Anode }}=300 \mu \mathrm{m}, \mathrm{d}=50 \mu \mathrm{m}( \pm 5 \mu \mathrm{m}), \mathrm{A}=(12 \times 12) \mathrm{mm}^{2}$



(d) $\mathrm{E}=90 \mathrm{MV} / \mathrm{m}, 11$ emitters $\mathrm{A}=(12 \times 12) \mathrm{mm}^{2}$

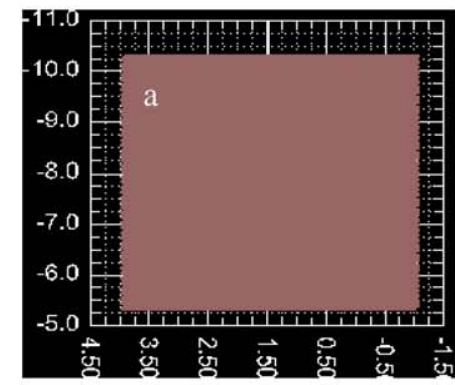

(e) $\mathrm{E}=120 \mathrm{MV} / \mathrm{m}, 0$ emitter $\mathrm{A}=(5 \times 5) \mathrm{mm}^{2}$

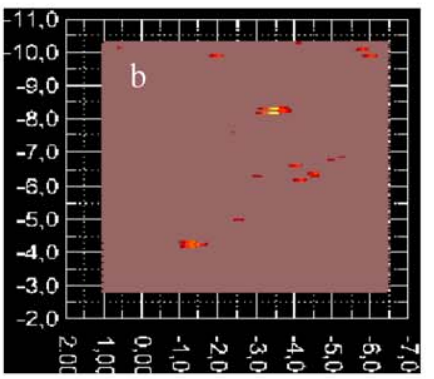

(f) $\mathrm{E}=120 \mathrm{MV} / \mathrm{m}, 17$ emitters $\mathrm{A}=(7.5 \times 7.5) \mathrm{mm}^{2}$

$2^{\text {nd }}$ Series: $\varnothing_{\text {Anode }}=100 \mu \mathrm{m}, \mathrm{d}=40 \mu \mathrm{m}( \pm 5 \mu \mathrm{m})$



(g) $\mathrm{E}=40 \mathrm{MV} / \mathrm{m}, 0$ emitter $3^{\text {rd }}$ Series:



(j) $\mathrm{E}=90 \mathrm{MV} / \mathrm{m}, 3$ emitters



(h) $\mathrm{E}=60 \mathrm{MV} / \mathrm{m}, 2$ emitters

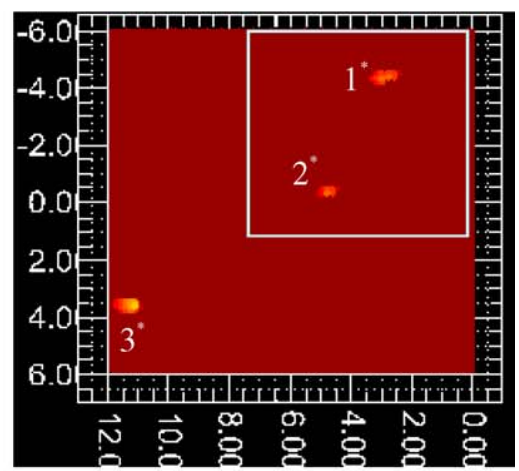

(i) $\mathrm{E}=90 \mathrm{MV} / \mathrm{m}, 3$ emitters

$\varnothing_{\text {Anode }}=300 \mu \mathrm{m}, \mathrm{d}=50 \mu \mathrm{m}( \pm 5 \mu \mathrm{m}), \mathrm{A}=(12 \times 12) \mathrm{mm}^{2}$

(k) $\mathrm{E}=120 \mathrm{MV} / \mathrm{m}, 8$ emitters

\section{$\mathrm{E}(\mathrm{MV} / \mathrm{m})$ \\ $\begin{array}{lllll}25 & 40 & 60 & 90 & 120\end{array}$}

Fig. 1. Voltage maps of the same EP Nb sample before (a-f) and after HPR (g-k) taken at different field levels and showing the onset field of emitters (see color bar). The maps in $(\mathrm{e}, \mathrm{f}, \mathrm{j}, \mathrm{k})$ correspond to the marked areas in $(\mathrm{d}, \mathrm{i})$ respectively (For interpretation of the references in colour in this figure legend, the reader is referred to the web version of this article). 
was cleaned in a new HPR facility at DESY with similar parameters as used for cavities, i.e. at a pump pressure of $150 \mathrm{bar}$, a rotation speed of $4-5 \mathrm{rpm}$ and a vertical speed of $10 \mathrm{~mm} / \mathrm{min}$.

FE measurements were performed under ultra high vacuum conditions $\left(<10^{-9}\right.$ mbar $)$. The sample stage is movable in $x y z$ directions by computer controlled motors with

Table 1

Number density of emitters for various anode diameters and electric fields extracted from Fig. 1

\begin{tabular}{lccc}
\hline$\emptyset_{\text {Anode }}(\mu \mathrm{m})$ & $E(\mathrm{MV} / \mathrm{m})$ & $N\left(\# / \mathrm{cm}^{2}\right)$ & \\
\cline { 3 - 4 } & & EP only & EP + HPR \\
\hline 300 & 40 & 0.7 & 0 \\
300 & 60 & 2.1 & 1.4 \\
300 & 90 & 4.2 & 2.1 \\
100 & 90 & 7.6 & 5.3 \\
100 & 120 & 30.2 & 14.2 \\
\hline
\end{tabular}

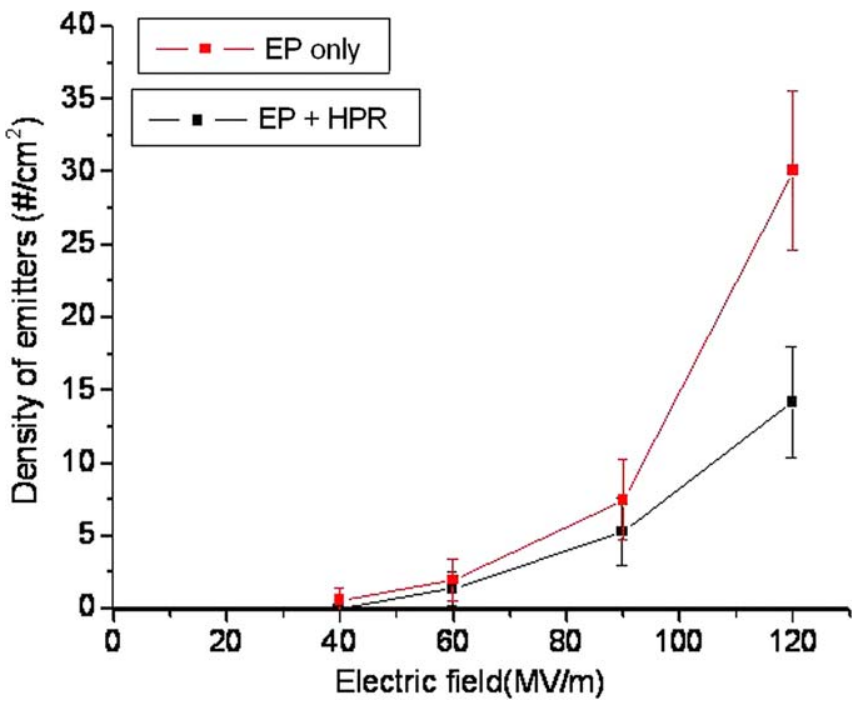

Fig. 2. Reduction of FE for SEP2 by HPR.

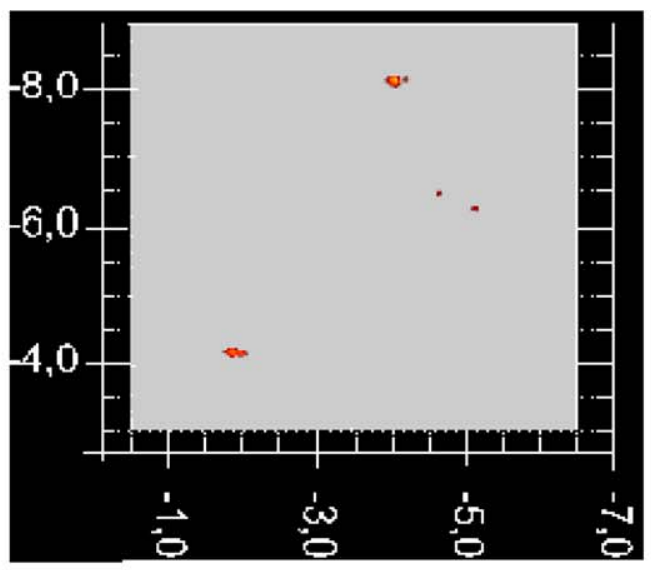

(a) $\mathrm{E}=80 \mathrm{MV} / \mathrm{m}, \mathrm{A}=6 \times 6 \mathrm{~mm}^{2}$



(b) $\mathrm{E}=83 \mathrm{MV} / \mathrm{m}, \mathrm{A}=1 \times 1 \mathrm{~mm}^{2}$

\section{$\mathrm{E}(\mathrm{MV} / \mathrm{m})$}

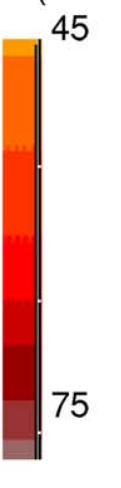

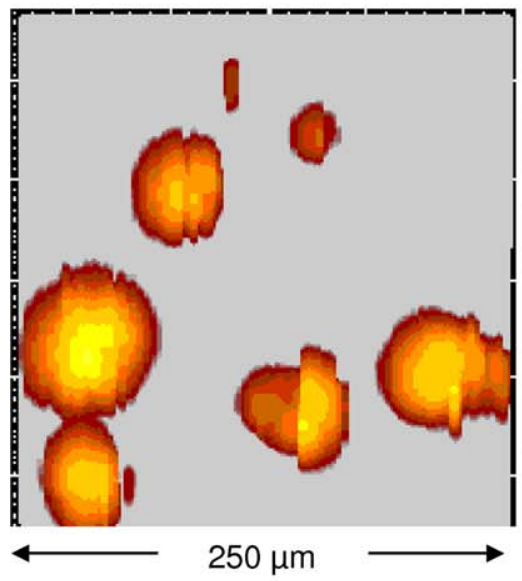
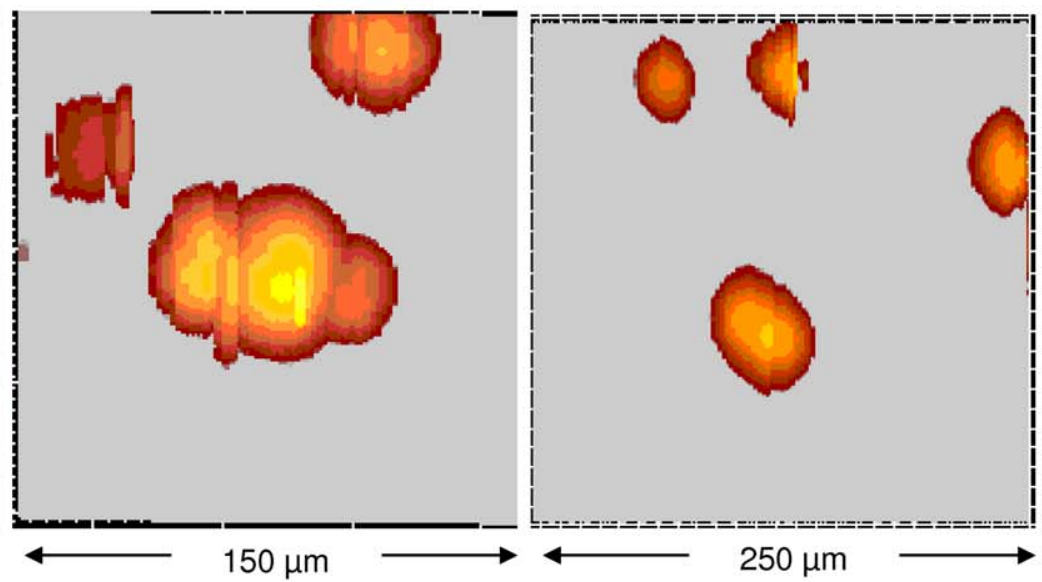

$\mathrm{E}(\mathrm{MV} / \mathrm{m})$

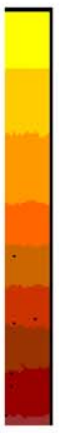

25

(c) $E=85 \mathrm{MV} / \mathrm{m}, \Delta \mathrm{z}=12 \mu \mathrm{m}, \alpha=4$ for emitters 1 (a) and (c), $\Delta \mathrm{z}=10 \mu \mathrm{m}, \alpha=3.5$ for emitter 1 (b)

Fig. 3. Zooming into emitters of sample SEP2 before HPR by high resolution maps with reduced anode diameter of (a) $30 \mu \mathrm{m}$, marked square resolved in (b) $10 \mu \mathrm{m}$ and emitters \#1 (a-c) resolved in (c) $2 \mu \mathrm{m}$. 
about $70 \mathrm{~nm}$ step width or by piezo translators with $\mathrm{nm}$ resolution. The electrode spacing, $d$, is controlled by a long distance optical microscope with CCD video camera and varies less than $1 \mu \mathrm{m}$ for well-tilted flat samples [3]. Emitter distributions were obtained by the voltage scans, $V(x, y)$, with a constant PID-regulated current of $1 \mathrm{nA}$, the spatial resolution of which is limited by the selected $\mathrm{W}$ anode and electrode spacing. Five different anodes (tip diameters $\varnothing_{\text {Anode }}=2-300 \mu \mathrm{m}$ ) were used for the complete series of measurements. The resulting typical measurement time for one map of $100 \times 100$ pixels is about $1 \mathrm{~h}$. At pronounced emitting sites, appropriate subroutines provide $V(z)$ plots at constant current ( $1 \mathrm{nA})$ for distance and field calibration and $I-V$ curves for Fowler-Nordheim (FN) analysis. Finally in situ SEM images with moderate spatial resolution $(\sim 1 \mu \mathrm{m})$ are taken as a guide for the relocalization of emitters in the high resolution SEM (nm) with EDX analysis. A more detailed description of the measurement techniques is given elsewhere [4].

\section{Results and discussion}

At first both $\mathrm{EP} \mathrm{Nb}$ samples were investigated in the FESM by regulated voltage scans up to $120 \mathrm{MV} / \mathrm{m}$. Sample SEP1 showed the onset of FE at $60 \mathrm{MV} / \mathrm{m}$ and about $11 \mathrm{emitters} / \mathrm{cm}^{2}$ at $90 \mathrm{MV} / \mathrm{m}$, which were clustered in a small part of the sample $\left(0.25 \mathrm{~cm}^{2}\right)$, while for most of the surface no FE occurred up to $120 \mathrm{MV} / \mathrm{m}$. The emitter distributions measured for sample SEP2 before and after HPR are shown in Fig. 1. It should be noted that the low resolution scan series (1st series before and 3rd series after HPR) were made in the same surface area of the sample, while the zoomed-in area of the 2nd and 4th series were slightly different according to the location of emitters.

In general, most of the emitters in Fig. $1(\mathrm{a}-\mathrm{f})$ and $(\mathrm{g}-\mathrm{k})$ are reproducible for increasing field level as well as for zooming into higher resolution, but some emitters become activated or better resolved then. As expected, sample SEP2 provides similar FE performance in terms of onset

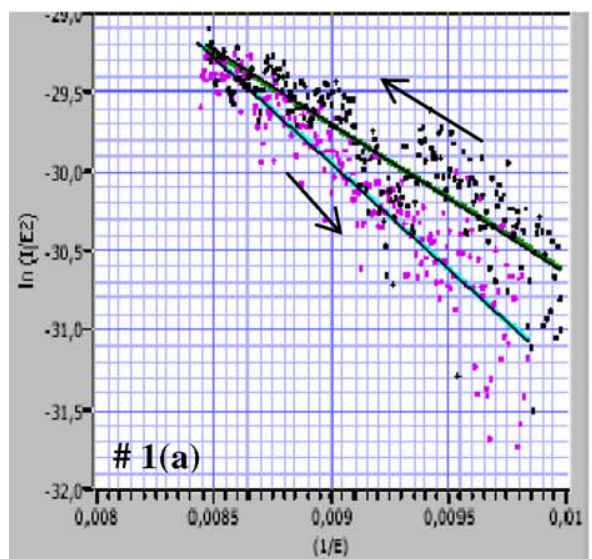

(a) $\mathrm{E}_{\text {on }}(1 \mathrm{nA})=33 \mathrm{MV} / \mathrm{m}$ $\beta \uparrow=231, \mathrm{~S}_{1}=3.23 \times 10^{-19} \mathrm{~m}^{2}$
$\beta_{\downarrow}=160, \mathrm{~S}_{2}=2.15 \times 10^{-17} \mathrm{~m}^{2}$



(d) $\mathrm{E}_{\text {on }}(1 \mathrm{nA})=68.7 \mathrm{MV} / \mathrm{m}$

$\beta_{\uparrow}=75.1, \mathrm{~S}_{1}=1.6 \times 10^{-15} \mathrm{~m}^{2}$

$\beta_{\downarrow}=64.6, \mathrm{~S}_{2}=2.4 \times 10^{-13} \mathrm{~m}^{2}$

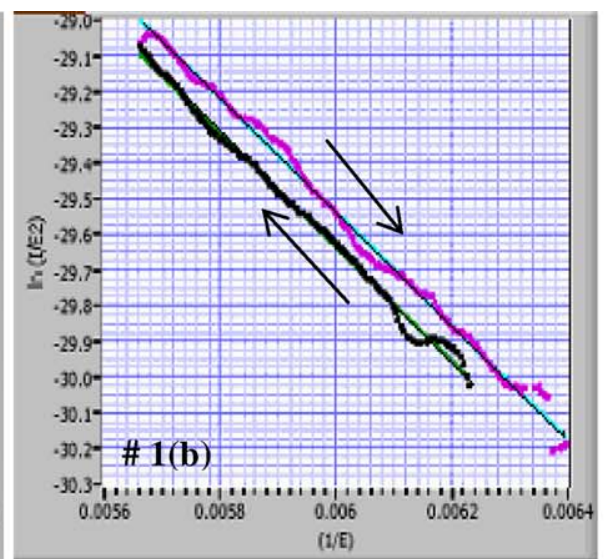

(b) $\mathrm{E}_{\mathrm{on}}(\ln \mathrm{A})=35 \mathrm{MV} / \mathrm{m}$

$\beta_{\uparrow}=133.5, \mathrm{~S}_{1}=3.7 \times 10^{-18} \mathrm{~m}^{2}$

$\beta_{\downarrow}=134, \quad S_{2}=3.9 \times 10^{-18} \mathrm{~m}^{2}$

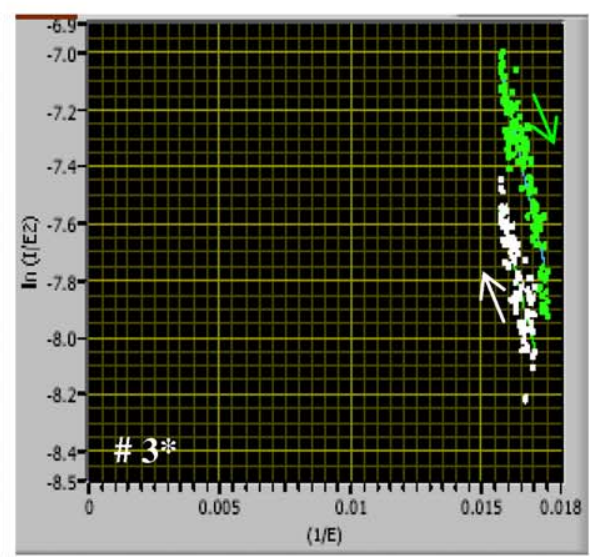

(e) $\mathrm{E}_{\text {on }}(1 \mathrm{nA})=48.5 \mathrm{MV} / \mathrm{m}$

$\beta_{\uparrow}=166.6, S_{1}=1.6 \times 10^{-20} \mathrm{~m}^{2}$

$\beta_{\downarrow}=147.6, \mathrm{~S}_{2}=7.2 \times 10^{-20} \mathrm{~m}^{2}$



(c) $\mathrm{E}_{\mathrm{on}}(\ln \mathrm{A})=45.5 \mathrm{MV} / \mathrm{m}$

$\beta_{\uparrow}=31.6, S_{1}=9 \times 10^{-13} \mathrm{~m}^{2}$

$\beta_{\downarrow}=31.85, \mathrm{~S}_{2}=7 \times 10^{-13} \mathrm{~m}^{2}$

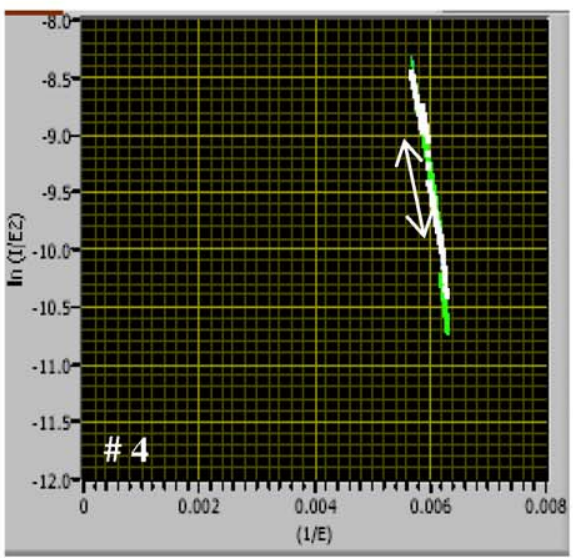

(f) $\mathrm{E}_{\mathrm{on}}(1 \mathrm{nA})=76.9 \mathrm{MV} / \mathrm{m}$

$\beta \uparrow=19.3, \mathrm{~S}_{1}=1 \times 10^{-13} \mathrm{~m}^{2}$

$\beta_{\downarrow}=17.9, S_{2}=5 \times 10^{-13} \mathrm{~m}^{2}$

Fig. 4. FN curves of single emitters \#1(a), 1(b) and 1(c) as marked in Fig. 3(b) and \# 1, 3 and 4 as marked in Fig. 1(k). $E_{\text {on }}$ is the onset field measured at 1 nA. $\beta \uparrow, \beta \downarrow$ and $\mathrm{S}_{1}, \mathrm{~S}_{2}$ represent the extracted $\beta$ values and $\mathrm{S}$ parameters from FN curves in up and down modes of changing electric field respectively. 
field and number density of emitters as sample SEP1 before HPR but improved values after HPR. Comparing Fig. 1(d) and (i) in detail, most of the emitters at $90 \mathrm{MV} / \mathrm{m}$ have been removed by HPR. In Fig. 1(f) and (k) at $120 \mathrm{MV} /$ $\mathrm{m}$, however, many weak emitters occur before as well as after HPR. The number density of emitters $N$ resulting from the maps for different resolution and electric field $E$ is given in Table 1. The comparison of these $N(E)$ data in Fig. 2 clearly proves the benefit of HPR against FE.

In order to learn more about the nature of the emitters, high resolution voltage scans were performed in the most interesting area (Fig. 1(f)) of sample SEP2 before HPR. In high resolution scans, the effective electric field between the electrodes in tip-plane configuration is $V /(\alpha \cdot d)$, where $\alpha$ is a geometric correction factor which depends on the tip geometry and electrode spacing [6]. Fig. 3(a) shows more emitters than the corresponding area in Fig. 1(d), thus demonstrating the activation of emitters by high fields. The strongest emission site there splits into three FE sites for $10 \mu \mathrm{m}$ resolution (Fig. 3(b)), which are further resolved in (Fig. 3(c)), where the resolution limit set by the actual surface roughness is reached.

Some of the emitters localized in Figs. 3(b) and 1(k) were chosen for stability and FN analysis as shown in Fig. 4. With exemption of the rather unstable emitter \#1(a), all emitters clearly showed stable metallic FN behav- iour partially with slight activation (e.g. \#1(b) and \#3*) or deactivation (e.g. $\# 1^{*}$ ) effects which are well known as switch-on/off due to unstable microstructures and surface influences [7]. Obviously the emitters on this EP Nb sample were stronger before than after HPR, i.e. the onset fields $E_{\text {on }}(1 \mathrm{nA})$ changed from $33-46 \mathrm{MV} / \mathrm{m}$ to $48-77 \mathrm{MV} / \mathrm{m}$. The field enhancement factors $\beta$ resulting from the slopes (for a work function $\Phi$ of $4 \mathrm{eV}$ ) vary less systematically between 31 and 231 and are balanced by the values of effective emission area, $S$, lying in the range of $10^{-20}$ and $10^{-12} \mathrm{~m}^{2}$. These values are typical for EFE of $\mathrm{Nb}$ surfaces and can be explained by the projection model of irregular shaped particulates of $\mu \mathrm{m}$ size [8] and resonant tunneling through electronic surface states [6].

It should be noted that only one emitter on SEP2 (\#2) has survived the HPR cleaning process but weakened as shown in Fig. 5(a-b). Initially, this emitter on the EP $\mathrm{Nb}$ sample with an $E_{\text {on }}(1 \mathrm{nA})$ of $45 \mathrm{MV} / \mathrm{m}$ switches from a low $\beta /$ high $S$ into a high $\beta /$ low $S$ state, the latter being much less emissive at fields around $50 \mathrm{MV} / \mathrm{m}$ (Fig.5(a)). After HPR this emitter $\left(\# 2^{*}\right)$ shows more stable emission in the field range $54-75 \mathrm{MV} / \mathrm{m}$ with as low $\beta$ values as in the initial state but $S$ parameters comparable to the final state before HPR. This puzzle might be clarified by the high resolution SEM images of this emitter in Fig. 5(c-e). Obviously a thin object of about $100 \mu \mathrm{m}^{2}$ size with a folded

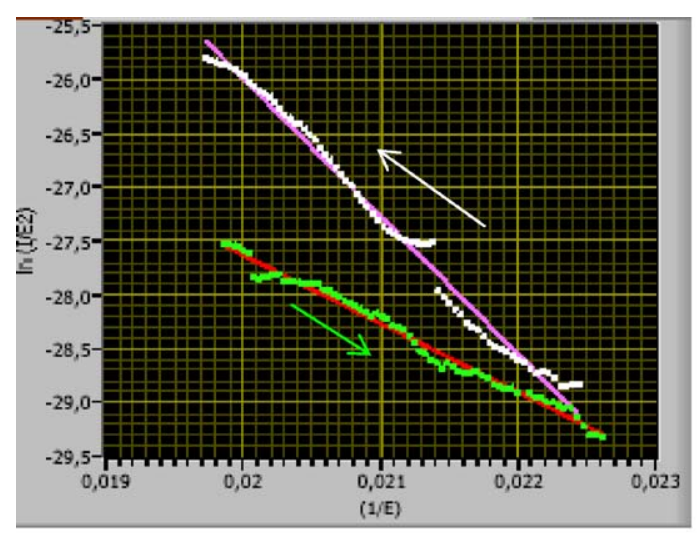

(a) $\quad \mathrm{E}_{\mathrm{on}}(1 \mathrm{nA})=44.6 \mathrm{MV} / \mathrm{m}$ $\beta_{\uparrow}=59.5, \mathrm{~S}_{1}=8.2 \times 10^{-10} \mathrm{~m}^{2}$ $\beta_{\downarrow}=119, \quad S_{2}=1.2 \times 10^{-16} \mathrm{~m}^{2}$



(b)

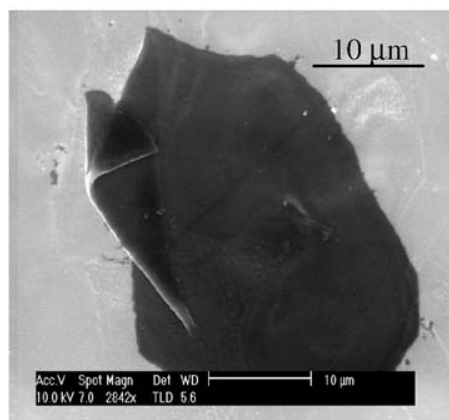

(c) Emitter \#2

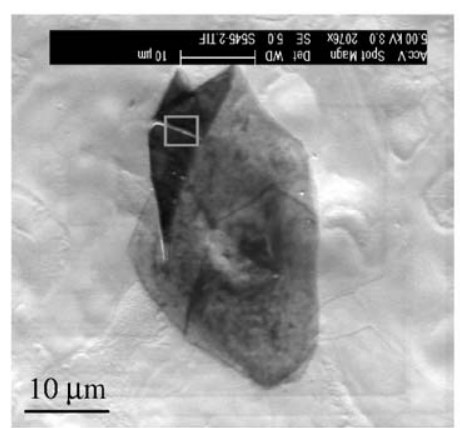

(d) Emitter \#2*

$$
\begin{aligned}
& \mathrm{E}_{\text {on }}(1 \mathrm{nA})=54.3 \mathrm{MV} / \mathrm{m} \\
& \beta_{\uparrow}=67.4, \quad \mathrm{~S}_{1}=2 \times 10^{-17} \mathrm{~m}^{2} \\
& \beta_{\downarrow}=51.2, \quad \mathrm{~S}_{2}=1.2 \times 10^{-15} \mathrm{~m}^{2}
\end{aligned}
$$



(e) marked edge of \# 2*

Fig. 5. FN curves and HRSEM images of the same emitter before (\#2) and after HPR (\#2*). Abbreviations are same as used in Fig. 4. 


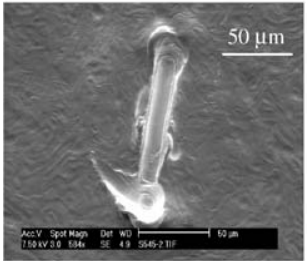

(a)

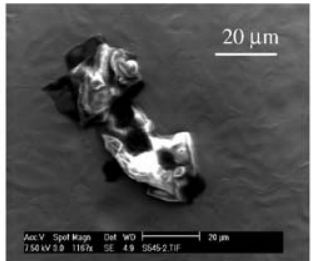

(b)



(c)

Fig. 6. SEM images of emitter \#3* (a) and \#4*(b). The EDX spectrum of \#4* (c) shows $\mathrm{S}, \mathrm{Cl}, \mathrm{K}$ contents.

edge extension and sharp protrusions covers the $\mathrm{Nb}$ surface, which seems to be conductive according to the dark colour in SEM. Most of this object is semi-transparent for the electron beam, and the grain structure is hardly influenced. At higher magnification submicron protrusions and a rolled edge of the extension become evident. Since no foreign element $(Z>10)$ was detected by EDX analysis, this object might reflect a different $\mathrm{Nb}$ oxide state compared to the regular surface as observed in star bursts [9]. It is tempting to attribute the change of FE parameters to the alignment of protrusions with electric field and dulling of sharp edges by HPR, but further FESM investigations with submicron resolution are required to prove any of such correlations.

Since HPR is regularly used for the surface preparation of $\mathrm{Nb}$ cavities, we have tried to identify all emitters found in Fig. 1(k) by SEM. While no obvious feature was found in the area of emitter $\# 1^{*}$, pronounced objects appeared in the SEM images for emitters $\# 3^{*}$ and $\# 4^{*}$. Fig. 6(a) shows a scratch-like surface irregularity of about $100 \mu \mathrm{m}$ length with terraced edges probably caused by a massive tool, but EDX analysis revealed only $\mathrm{Nb}$ there. Therefore, strong but very local geometric field enhancement can be expected which fits to the high $\beta$ and low $S$ value of emitter $\# 3^{*}$. In contrast Fig. 6(b) shows a crystalline particle of some $10 \mu \mathrm{m}$ size with some edges, which fit well to the measured $\beta$ and $S$ values of emitter \#4*. This particle partially consists of $\mathrm{S}, \mathrm{Cl}$ and $\mathrm{K}$ as revealed by the EDX spectrum in Fig. 6(c). Considering the large size of all identified objects, the EFE of $\mathrm{Nb}$ should be reducible by improved surface preparation techniques.

\section{Conclusions}

Systematic FE scans of EP Nb samples have given onset fields of 40-60 MV/m and emitter number densities up to $30 / \mathrm{cm}^{2}$ at $120 \mathrm{MV} / \mathrm{m}$ which were about halved after HPR. Since some of the emitters might have been welded on the surface by the FE current, further reduction is expected for EP samples directly cleaned by HPR. The strongest of these emitters were localized on a $\mu \mathrm{m}$ scale. Most of them showed stable FN-like $I-V$ curves with values of 31-231 and $S$-parameters of $10^{-12}-10^{-20} \mathrm{~m}^{2}$ which are typical for particulates and surface irregularities on $\mathrm{Nb}$. Some emitters were identified by high resolution SEM and EDX investigations. The only HPR resistant emitter turned out to be a thin conductive object with a folded edge and submicron protrusions, which mainly consists of $\mathrm{Nb}$. Moreover, a scratch-like surface defect and a crystalline particle with $\mathrm{S}, \mathrm{Cl}$ and $\mathrm{K}$ content were found as emitters after HPR. The rather large size and nature of these identified objects gives hope to avoid $\mathrm{FE}$ in $\mathrm{Nb}$ cavities by improved surface preparation techniques up to the fields required for XFEL and ILC.

\section{Acknowledgements}

We would like to acknowledge Claire Antoine and Alain Aspart from CEA Saclay for electropolishing of the samples and wish to thank the Electrical Engineering Department at the University of Wuppertal for providing SEM and EDX facilities. The support of the European Community Research Infrastructure Activity under FP6 "Structuring the European Research Area" program (CARE, contract number RII3-CT-2003-506395) is gratefully acknowledged.

\section{References}

[1] R. Brinkmann, et al. (Eds.), TESLA XFEL Technical Design Report Supplement, DESY 2002-167, 2002; K. Floettmann, in: Proc. of 12th International Workshop on RF-Superconductivity, Cornell Univ., USA, 2005.

[2] I.V. Bazarov, H. Padamsee, TESLA Report 2005-09, in: Proc. of 12th International Workshop on RF-Superconductivity, Cornell Univ., USA, 2005.

[3] E. Mahner, N. Minatti, H. Piel, N. Pupter, Appl. Surf. Sci. 67 (1993) 23.

[4] D. Lysenkov, G. Müller, Int. J. Nanotechnol. 2 (2005) 239.

[5] D. Reschke, A. Brinkmann, D. Werner, G. Müller, in: Proc. Lin. Acc. Conf., Lübeck 2004.

[6] T. Habermann, Thesis, University of Wuppertal, WUB-DIS 98-18 (1999).

[7] T. Habermann, A. Göhl, D. Nau, G. Müller, H. Piel, M. Wedel, Part Acc. 61 (1998) 137.

[8] M. Jimenez, R.J. Noer, G. Gouve, J. Jodet, B. Bonin, J. Phys. D: Appl. Phys. 27 (1994) 1038.

[9] J. Knobloch, H. Padamsee, Part. Acc. 61 (1998) 169. 